\title{
RELATO FINANCEIRO ELETRÓNICO: AS NECESSIDADES DOS UTILIZADORES NO CASO ANGOLANO
}

\section{Rui Filipe Cerqueira Quaresma}

Departamento de Gestão, Escola de Ciências Sociais, Universidade de Évora, Portugal

Gilberto Moisés Moma Capeça

Departamento de Gestão de Risco do Banco Nacional de Angola, Angola

Ana Fialho

Departamento de Gestão, Escola de Ciências Sociais, Universidade de Évora, Portugal

\section{RESUMO}

O relato financeiro eletrónico é uma realidade tornada possível com o aparecimento da Internet, cada vez mais utilizado pelas empresas na divulgação da informação contabilístico-financeira. Embora seja uma área de investigação relativamente recente, existem já diversos estudos e recomendações no sentido de as empresas potenciarem as suas possibilidades. Contudo, é mais escassa a investigação publicada que incida no lado da procura da informação contabilísticofinanceira e que identifique as necessidades dos utilizadores quanto ao formato e conteúdo dessa informação. Assim, o objetivo deste estudo é verificar se as necessidades e interesses dos utilizadores deste tipo de informação, num mercado bolsista emergente, como é o caso de Angola, coincidem, ou não, com as recomendações e modelos de divulgação atuais. Concluímos que as necessidades dos utilizadores estudados correspondem às recomendações atuais, quanto ao formato de apresentação da informação contabilístico-financeira e respetivo conteúdo, devendo ser consideradas como referência pelas empresas que vão integrar o mercado bolsista emergente angolano. Este trabalho apresenta dois contributos: por um lado, a análise na perspetiva da procura da informação e, por outro lado, o estudo desta temática num mercado emergente, o que permitirá aos organismos reguladoras definir regras e recomendações antecipadamente, no que respeita ao relato financeiro eletrónico.

Palavras-Chave: Internet, páginas web, relato financeiro eletrónico.

Manuscript first received/Recebido em: 2016/Jan/21 Manuscript accepted/Aprovado em: 2017/Jul/31

Address for correspondence / Endereço para correspondência:

Rui Filipe Cerqueira Quaresma, Universidade de Évora, Évora, Portugal http://orcid.org/0000-0002-1970-9277,

E-mail quaresma@uevora.pt

Gilberto Moisés Moma Capeça, Banco Nacional de Angola, Faculdade de Economia da Universidade Agostinho Neto, Angola E-mail gilbertocapessa@hotmail.com

Ana Fialho, Departamento de Gestão, Escola de Ciências Sociais, Universidade de Évora, Largo dos Colegiais, 2, 7000-803 Évora, Portugal. E-mail afialho@uevora.pt 


\section{INTRODUÇÃO}

Com o aparecimento da Internet, um dos meios mais importantes e rápidos para a transmissão, receção e publicação de informação, surgiu uma nova forma de relato financeiro, o relato financeiro eletrónico, o qual permite aos utilizadores da informação financeira um mais rápido acesso à informação necessária à tomada de decisão.

A Internet não só introduziu profundas alterações na forma como as organizações se relacionam com os diversos stakeholders como, e de acordo com (Alves, 2005), associado ao correio eletrónico e às novas linguagens informáticas, contribuiu de forma significativa para a democratização do relato financeiro eletrónico. Por outro lado, e segundo (Craven \& Marston, 1999), o desenvolvimento das tecnologias de informação e comunicação está a contribuir para que as empresas, de forma voluntária, relatem a sua informação financeira na Internet, utilizando os respetivos sítios web.

Segundo (O'Kelly, 2000), o ganho da Internet como meio para divulgação de relatórios de informação de negócios tem alterado o fluxo da informação das empresas para os investidores e credores. O tradicional paradigma de relatórios em papel continuará a desaparecer, dando lugar aos relatórios online. Os utilizadores da informação contabilísticofinanceira encontram um novo meio para a recolha e análise da informação. Segundo este autor, a procura do relato financeiro online por parte dos utilizadores é justificada por fatores característicos da Internet, como o acesso, a imediatez, a riqueza, a conectividade e a interatividade.

A utilização da Internet, por parte das empresas, para divulgar as suas informações contabilístico-financeiras é uma prática que, por um lado, e segundo vários autores ( (Marston \& Polei, 2004); (Xiao, Yang, \& Chow, 2004); (León, 2003); (Oyelere, Laswad, \& Fisher, 2003), (Ashbaugh, Johnstone, \& Warfield, 1999) e (Lymer, 1999)), demonstra que a empresa é moderna e procura chegar a um grande número de utilizadores de informação contabilísticofinanceira, principalmente os investidores. Por outro lado, e como também é referido na literatura ( (Silva \& Filho, 2005); (Geerings, Bollen, \& Hassink, 2003); (Silva \& Quaresma, 2001); (Deller, Stubenrath, \& Goethe, 1999); (Hedlin, 1999) e (Lymer, 1999)), esta nova forma de relato financeiro tem trazido ganhos no relacionamento entre empresas e investidores.

No trabalho de revisão bibliográfica que realizámos foi possível verificar que a preocupação dos investigadores, académicos, reguladores e profissionais se tem centrado, essencialmente, em conhecer e explicar as questões do lado da oferta da informação, incidindo na importância da divulgação da informação contabilístico-financeira através da Internet e produzindo um conjunto variado de recomendações.

Logo, é importante que as empresas tenham um sítio web disponível e de fácil acesso para fazer a divulgação da sua informação contabilístico-financeira. Contudo, isso pode não ser suficiente, pois as empresas têm também que saber se a informação disponibilizada é, realmente, a que os utilizadores procuram e que lhes é útil para a tomada de decisão.

É com base neste pressuposto que pretendemos verificar se as necessidades e interesses dos utilizadores deste tipo de informação, num mercado bolsista emergente, como é o caso de Angola, coincidem com as recomendações que regem atualmente a forma e conteúdo da informação divulgada pelas empresas. 


\section{REVISÃO DA LITERATURA}

A Internet contribuiu de forma significativa para alterar a forma como as pessoas e as organizações comunicam, atendendo às vantagens que oferece e à facilidade de uso. Contudo, e embora essas alterações já influenciem o modo como as empresas divulgam os seus relatórios financeiros, há necessidade de regular a utilização deste canal. Como referem (Inchaustin \& Jorge, 2002), o uso da Internet amplia a possibilidade de gestão da informação empresarial, e oferece outras formas de fazer comércio, publicidade e de comunicação da informação financeira para o exterior.

Para (Alves, 2005) o relato financeiro eletrónico é resultado de uma evolução inequívoca, respondendo às necessidades e dificuldades sentidas, quer pelos utilizadores, quer pelas próprias empresas, permitindo: reduzir o custo e o tempo na divulgação da informação financeira; comunicar com um maior número de utilizadores e potenciais investidores; ultrapassar as limitações do relato tradicional; aumentar a quantidade e tipo de informação a divulgar. Contudo, e como refere a mesma autora, estas transformações implicam a realização de uma análise aprofundada das principais consequências que este novo meio de comunicação tem no processo de divulgação da informação financeira.

Rodrigues \& Menezes (2001) também acreditavam que a Internet ia conduzir o relato financeiro de ciclos anuais e semestrais para o relato em tempo real. Contudo, tal ainda não acontece, dado que se continua a oferecer o mesmo tipo de informação, por vezes insuficiente. Para que esta vantagem se concretize é necessário resolver aspetos de natureza prática e legal, nomeadamente, a integração da informação corrente com a informação previamente apresentada, sem que para isso a empresa incorra em custos significativos e problemas legais.

Como referia (O'Kelly, 2000), a capacidade da informação ser mais atempada e mais relevante originará uma maior eficiência nos mercados de capitais, traduzindo-se numa maior eficiência de custos e rapidez, quer por parte dos investidores, quer por parte dos mercados financeiros.

Segundo (León, 2003), embora se assista à massificação do uso das novas tecnologias no processo de comunicação da informação contabilístico-financeira, existem ainda poucos guias de atuação, resultando daí uma grande diversidade nos conteúdos e formatos das informações apresentadas pelas empresas.

A ausência de referenciais pode conduzir as empresas, que divulgam este tipo de informação, a incorrerem em alguns riscos, nomeadamente os relacionados com inclusão de informação previsional, informação de analistas, transcrição das conferências e/ou discursos, extratos de contas anuais, informação auditada e não auditada, atualização da informação, informação sobre os produtos da empresa, possibilidade de alterar a informação, informação em tempo real, informação interativa.

\section{RECOMENDAÇÕES E ORIENTAÇÕES}

Vários organismos verificando o crescimento do relato financeiro eletrónico e preocupados com a idoneidade das informações veiculadas pela Internet, definiram regras e recomendações de boas práticas para a divulgação e acessibilidade deste tipo de informação. Entre estes organismos destacamos o International Accounting Standards Committee (IASC), 
que mais tarde evoluiu para International Accounting Standards Board (IASB), o Financial Accounting Standards Board (FASB), a Comissão do Mercado de Valores Mobiliários (CMVM) portuguesa e a Asociación Española de Contabilidad y Administración (AECA).

Em 1999, o (IASC, 1999) publicou um estudo, que seria uma primeira etapa de um possível projeto para o desenvolvimento de normas contabilísticas sobre a divulgação de informação financeira através da Internet. Dessas recomendações destacamos: a informação divulgada na Internet não deve ser diferente das outras versões publicadas; quando não se não se disponibilizar a informação que consta no Relatório e Contas na íntegra, esse facto deverá ser mencionado no respetivo sítio web, tal como se se divulgar informação adicional; no relato financeiro eletrónico deve-se mencionar quais os conteúdos divulgados que foram auditados, bem como o teor do relatório de auditoria; se a informação em formato eletrónico se encontrar repartida por vários ficheiros, a entidade deverá apresentar uma listagem completa desses ficheiros e da sequência que existe entre eles; deverão constar as assinaturas digitais nos documentos eletrónicos, nomeadamente nos documentos cuja autenticidade possa ser questionada.

Para o (FASB, 2000) era importante que as empresas que divulgassem informação financeira na Internet tivessem em atenção determinados requisitos, nomeadamente: a inclusão de informação prospetiva ou links para sites de analistas ou de comentários de terceiros sobre a empresa, mencionando os termos de responsabilidade; divulgação das demonstrações financeiras completas e de todos os outros documentos de prestação de contas; contextualização da informação divulgada.

A (CMVM, 2000) publicou um conjunto de orientações das quais se destacam os entendimentos e recomendações quanto à informação a divulgar através da Internet e os entendimentos resultantes dos princípios da neutralidade e da equivalência. No que se refere aos entendimentos da CMVM relativamente ao conteúdo da informação a divulgar destacamos: a data da última atualização da informação ou da fonte da informação; mencionar se a informação se refere a um documento integral, extrato ou resumo; indicar se a informação está ou não aprovada e auditada.

Relativamente aos entendimentos resultantes dos princípios da neutralidade e da equivalência, a CMVM determina o seguinte: as exigências da entidade de supervisão mantêmse independentemente do tipo de relato; responsabilização das entidades pelo conteúdo divulgado e pelos procedimentos relacionados com a conservação em arquivos de documentos e registos; garantir que os documentos disponibilizados em formato eletrónico têm níveis equivalentes de inteligibilidade, de durabilidade, de autenticidade e de integridade aos exigidos nos documentos em suporte de papel e que a organização dos arquivos informáticos seja inviolável e garanta a inalterabilidade dos conteúdos e acessos dos mesmos.

A CMVM recomenda ainda, tendo em conta os entendimentos referidos, que seja disponibilizado para cada sítio na Internet um endereço de correio eletrónico que permita o contacto com a entidade responsável pela divulgação da informação financeira.

A (AECA, 2002) elaborou um documento exaustivo, focado num conjunto de recomendações para a divulgação da informação financeira na Internet, organizado em torno de diversos tópicos, dos quais destacamos: Conteúdos mínimos, Responsabilidade das 
empresas, Identificação das páginas web, Reciprocidade com a informação publicada noutros formatos e Alcance da Auditoria.

\section{INVESTIGAÇÃO DESENVOLVIDA}

A investigação desenvolvida sobre o tema do relato financeiro eletrónico (ver Tabela I), pode ser dividida em três grupos:

- Estudos que caracterizam o estádio de desenvolvimento da utilização/aplicação do relato financeiro eletrónico de um determinado país:

- Entre os países estudados encontram-se, entre outros, a África do Sul, a Alemanha, a Áustria, o Brasil, a China, a Croácia, a Espanha, o Japão, o México, a Nigéria, Portugal, o Reino Unido e a Suécia.

- Nos artigos é possível verificar que, nos países estudados, a Internet se tem expandido como meio para apresentação da informação financeira através dos sítios $w e b$ e que a maior parte das empresas analisadas, principalmente as cotadas na bolsa de valores, usam a Internet para a divulgação de informação financeira e não financeira.

- Verificou-se também que o tamanho da empresa tem uma influência positiva na divulgação dessas informações, explicando não só a quantidade, mas também a qualidade da informação financeira que é divulgada. Verifica-se, por outro lado, que não existe uma associação clara entre o sector de atividade da empresa e a divulgação de informação financeira.

- Estudos comparativos entre empresas e/ou entre países:

○ Nos estudos são feitas comparações relativamente à divulgação de informação contabilístico-financeira na Internet, à existência ou não de sítios web, principalmente para empresas cotadas na bolsa de valores.

- Entre outras conclusões referidas nos estudos, destaca-se o facto de não existirem diferenças significativas, em termos de qualidade dos sítios web, das empresas que estão cotadas em bolsa.

- Verificou-se também que, nos países estudados, são sobretudo as empresas de topo que estão mais preocupadas com a divulgação de informação financeira na Internet.

- Estudos ou documentos normativos que pretendem regulamentar ou emitir normas de conduta:

○ Existem vários estudos, baseados em códigos de conduta para a divulgação da informação contabilístico-financeira na Internet, onde se destaca: a responsabilização dos divulgadores destas informações quanto aos conteúdos por si publicados; a necessidade de se assinalar um nível mínimo de responsabilidade a todas as partes implicadas no processo de divulgação de informação financeira; a responsabilidade dos auditores em assegurar que nos sítios web das empresas são 
identificadas claramente as informações que foram auditadas e as que não foram objeto de um processo de auditoria.

- Estudos com recomendações quanto à forma e conteúdo da informação contabilístico-financeira, onde se destaca a necessidade de padronização relativamente à forma de divulgação da informação publicada na Internet e se referem os tipos de utilizadores desta informação e os conteúdos que mais procuram.

Tabela 1. Principais estudos realizados sobre o Relato Financeiro Eletrónico

\begin{tabular}{|c|c|}
\hline Tema & Autores \\
\hline Estudos que caracterizam a realidade de um determinado país & $\begin{array}{l}\text { (Salawu, 2013); (Pervan, 2005); (Silva \& } \\
\text { Filho, 2005); (Barak, 2004); (Marston \& } \\
\text { Polei, 2004); (Xiao, Yang, \& Chow, } \\
\text { 2004); (Larran \& Giner, 2002); (Marston, } \\
\text { 2003); (Pérez \& Delgado, 2002); (Silva \& } \\
\text { Quaresma, 2001); (Craven \& Marston, } \\
\text { 1999); (Hedlin, 1999) }\end{array}$ \\
\hline $\begin{array}{l}\text { Estudos que fazem algum tipo de comparação entre empresas } \\
\text { ou países }\end{array}$ & $\begin{array}{l}\text { (Alves, 2005); (Barak, 2004); (Marston \& } \\
\text { Polei, 2004); (Geerings, Bollen, \& } \\
\text { Hassink, 2003); (Craven \& Marston, } \\
\text { 1999); (Deller, Stubenrath, \& Goethe, } \\
\text { 1999); (Pirchegger \& Wagenhofer, 1999); } \\
\text { (Westarp, Dieter, Stubernat, Buxmann, \& } \\
\text { Konig, 1999) }\end{array}$ \\
\hline Estudos ou documentos que contemplam recomendações & $\begin{array}{l}\text { (Dominguez \& Gallego, 2006); (Smith \& } \\
\text { Pierce, 2005); (Fisher, Oyelere, \& Laswad, } \\
\text { 2004); (León, 2003); (Debreceny, Gray, \& } \\
\text { Mock, 2001); (Lymer, 1999); (Lymer, } \\
\text { Debreceny, Gray, \& Rahman, 1999); } \\
\text { (Oyelere, Laswad, \& Fisher, 2003); } \\
\text { (Westarp, Dieter, Stubernat, Buxmann, \& } \\
\text { Konig, 1999); (Quagli \& Riva, 2005); } \\
\text { (Beattie \& Pratt, 2003) }\end{array}$ \\
\hline
\end{tabular}

\section{AMOSTRA E METODOLOGIA}

O objetivo deste trabalho é verificar se as necessidades e interesses dos utilizadores da informação financeira, num mercado bolsista emergente, como é o caso de Angola, coincidem com as atuais recomendações nesta matéria. Para alcançarmos este objetivo foi necessário primeiro identificar os grupos de utilizadores a estudar e, numa segunda etapa, identificar as necessidades e interesses desses grupos. 
Assim, optou-se por utilizar uma amostra por conveniência que é composta por grupos de utilizadores representativos do universo dos utilizadores deste tipo de informação. A seleção dos elementos que compõem a amostra teve por base as categorias definidas anteriormente por (Debreceny, Gray, \& Mock, 2001); (Beattie \& Pratt, 2003); (Quagli \& Riva, 2005).

Deste modo, foram selecionados elementos dos seguintes grupos de utilizadores: Analistas de crédito, Gestores financeiros, Auditores financeiros e Supervisores financeiros. Para além destes elementos, foram ainda selecionados dois "Diretores" que, não estando classificados dentro daqueles grupos, utilizam também este tipo de informação, ou seja, entendemos que seria importante obter contributos deste tipo de utilizador para minimizar alguns riscos associados a vícios relacionados com o processo diário de utilização desta informação, presentes nos grupos de utilizadores definidos.

Na seleção dos elementos da amostra foi ainda considerada a formação académica, a sua atividade profissional e o facto de desempenharem funções relacionadas com $\mathrm{o}$ tratamento/análise de informação contabilístico-financeira em organizações angolanas.

A recolha dos dados foi realizada através de entrevistas semiestruturadas, tendo por base um guião com perguntas abertas, antecipadamente enviado aos entrevistados, para se familiarizarem com as questões. As perguntas incluídas no guião foram redigidas tendo em atenção os diversos estudos ou documentos que contemplam recomendações quanto à divulgação de informação contabilístico-financeira, indicados na Tabela I, bem como algumas das regras referidos por diversos organismos, nomeadamente ( (IASC, 1999); (FASB, 2000); (CMVM, 2000); (AECA, 2002)).

$\mathrm{Na}$ Tabela II apresentamos uma caracterização da amostra, quanto ao grupo de utilizadores a que pertencem e ao tipo de formação académica. 
Tabela 2. Caracterização da amostra

\begin{tabular}{|c|c|c|c|}
\hline & & Número & $\%$ \\
\hline \multirow{5}{*}{ Categoria } & Analista de crédito & 10 & 29,4 \\
\hline & Gestor Financeiro & 8 & 23,5 \\
\hline & Auditor Financeiro & 8 & 23,5 \\
\hline & Supervisor Financeiro & 6 & 17,6 \\
\hline & Diretor & 2 & 5,88 \\
\hline \multirow{5}{*}{ Formação académica } & Lic. Gestão de Empresas & 12 & 35,3 \\
\hline & Lic. Economia & 8 & 23,5 \\
\hline & $\begin{array}{l}\text { Lic. Contabilidade e } \\
\text { Gestão }\end{array}$ & 7 & 20,6 \\
\hline & Lic. Eng ${ }^{a}$ Informática & 4 & 11,8 \\
\hline & $\begin{array}{l}\text { Lic. Informática de } \\
\text { Gestão }\end{array}$ & 3 & 8,8 \\
\hline
\end{tabular}

Como se pode observar pelos dados apresentados, foram entrevistados indivíduos de diversas categorias, o que aconteceu pelo facto de pretendermos recolher opiniões de utilizadores que, porque desempenham tarefas/atividades diferentes, provavelmente têm pontos de vista diferentes quanto à forma e ao conteúdo das informações financeiras divulgadas pelas empresas na Internet. Quanto à formação académica, todos os entrevistados têm o grau de licenciado, aspeto importante pois a análise deste tipo de informação requer competências que normalmente só se obtém com este nível de formação; por outro lado, e com exceção dos quatro licenciados em Engenharia Informática, os entrevistados têm formações académicas que contemplam, de uma maneira geral, matérias relacionadas com a contabilidade e as áreas financeiras. No caso dos licenciados em Engenharia Informática, estes foram escolhidos atendendo às funções que desempenham, e que implicam a análise deste tipo de dados. 
Após a realização das entrevistas, as quais foram realizadas com recurso a suporte áudio e, posteriormente, transcritas para texto, os dados foram sujeitos a uma primeira avaliação que permitiu verificar a consistência das respostas obtidas. Seguidamente, esses dados foram objeto de um processo de análise de conteúdo, possibilitando a identificação dos aspetos mais importantes relativamente às respostas dos entrevistados.

\section{RESULTADOS E DISCUSSÃO}

Apresentamos neste ponto a análise efetuada às respostas obtidas para as 12 questões que faziam parte do guião da entrevista (para além das questões de identificação do entrevistado).

\section{Qual a melhor forma para consultar a informação contabilístico-financeiro - formato papel ou formato eletrónico?}

A maioria dos entrevistados considera ser o formato eletrónico (sítio web), o melhor formato para consultar a informação contabilístico-financeira das empresas, porque aumenta a facilidade de acesso à informação por parte dos diversos stakeholders e aumenta a pressão para a melhoria contínua da qualidade da informação publicada por parte das empresas. Por outro lado, a maioria dos entrevistados considera que nos sítios web é mais fácil realizar o download dessas informações e é também mais fácil o seu armazenamento.

A opinião dos entrevistados coincide com as recomendações dos organismos e de diversos estudos realizados ( (Lymer, 1999); (Lymer, Debreceny, Gray, \& Rahman, 1999); (AECA, 2002); (Beattie \& Pratt, 2003); (Quagli \& Riva, 2005)), que indicam que a melhor forma de consultar a informação contabilístico-financeira é através dos sítios web, pois é um meio acessível para todos os utilizadores, reduz os custos de impressão e de divulgação e aumenta a facilidade de tratamento da informação.

\section{Qual a melhor forma de apresentação através da Internet: ficheiros PDF, páginas HTML, ficheiros tipo Excel ou Word, outros formatos?}

Com exceção de um entrevistado, todos os restantes referiram que os ficheiros tipo Excel são os mais adequados para aceder às informações contabilístico-financeiras. Todos são de opinião que o formato PDF é mais seguro, por não permitir a alteração dos dados.

A escolha, quase unânime, pelos ficheiros tipo Excel deve-se ao facto de, em Angola, os utilizadores terem alguma dificuldade na obtenção/instalação de determinadas ferramentas/programas, como é o caso do Acrobat Reader, necessário para consultar os ficheiros em formato PDF. O acesso aos ficheiros tipo Excel acaba por ser mais simples, no caso angolano, dado que a aplicação necessária para consultar e manipular estes ficheiros integra o pacote Office, que já está instalado no computador que é colocado à disposição do utilizador. Quanto ao Acrobat Reader, e apesar de poder ser descarregado sem custos através da Internet, o utilizador, para o instalar no seu computador, tem que recorrer a um técnico da área de apoio ao utilizador, pois, por norma, a instalação de novo software requer um perfil de administrador de sistema. 
Neste assunto, os estudos de ( (Lymer, Debreceny, Gray, \& Rahman, 1999); (AECA, 2002); (Barak, 2004); (Alves, 2005)) referem a possibilidade de utilização dos vários formatos (PDF, HTML, formatos tipo Excel ou Word e XBRL) para apresentação deste tipo de informação, destacando (Alves, 2005) o formato PDF como o mais indicado se o objetivo for divulgar na Internet uma versão análoga à do relatório em papel, e o formato HTML quando o tempo de descarregamento da informação e a forma de manusear a informação são os aspetos mais importantes.

\section{Deve existir uma "zona" própria no sítio web para os investidores/acionistas ou é preferível uma página específica? Porquê?}

Nesta questão as opiniões dos entrevistados dividiram-se, cerca de $50 \%$ considera relevante a existência de um endereço diferente para os investidores/acionistas. Esta preferência tem a ver, segundo os entrevistados, com o facto de os investidores/acionistas procurarem informação específica, o que lhes permitiria, caso houvesse um endereço diferente, aceder à informação com mais facilidade. Como os investidores necessitam geralmente de informações sobre o desempenho financeiro da empresa, a estrutura acionista e os seus responsáveis, e geralmente estas informações são acompanhadas de gráficos, imagens e às vezes até gravações áudio de discursos de responsáveis da empresa, essas informações podem sobrecarregar o sítio web, tornando desta forma mais difícil aceder aos conteúdos destes sítios.

A outra parte dos entrevistados considera irrelevante a existência de uma zona no sítio web da empresa destinada aos investidores/acionistas, entendem não ser necessário haver uma área para informação relacionada com investidores e/ou acionistas desde que a informação no sítio web esteja bem organizada e seja de fácil localização. Consideram ainda que a informação que os investidores/acionistas procuram também tem interesse para os outros visitantes do sítio web da empresa.

Segundo diversas recomendações ( (AECA, 2002); (Peréz, Martinez, \& Martín, 2002); (León, 2003)), é importante que as empresas criem endereços específicos dentro das páginas Web que agrupem toda a informação contabilístico-financeira oferecida. Esta informação deverá ser acessível diretamente desde a página principal, selecionando uma opção que permita lá chegar, como por exemplo, "informação para acionistas".

\section{Quais os conteúdos/informações que devem ser divulgadas através da Internet?}

Os entrevistados são de opinião que o Balanço, a Demonstração de Resultados e a Demonstração dos Fluxos de Caixa são fundamentais na apresentação da informação contabilístico-financeira das empresas. Os entrevistados consideram também como relevante a necessidade de disponibilização destas Demonstrações Financeiras numa base semestral e/ou anual, o que permitiria conhecer a evolução da situação financeira e económica da empresa.

Se tivermos em atenção as recomendações dos organismos e dos investigadores ( (FASB, 2000); (AECA, 2002); (Quagli \& Riva, 2005)), verificamos que as informações que os utilizadores angolanos procuram coincidem com aquelas recomendações. 
Disponibilizar a mesma informação no papel e na Internet ou mais informação na Internet? Deve haver alguma advertência se for disponibilizada mais informação na Internet? Porquê?

Nesta questão os entrevistados foram consensuais na necessidade de existir coincidência entre os conteúdos nos diferentes formatos de divulgação da informação. Se a informação não coincidir, deve existir uma advertência para que os utilizadores saibam que não estão a ter acesso a informação completa, analisando-a com as devidas reservas. Também neste tópico a opinião dos entrevistados coincide com as recomendações analisadas ( (CMVM, 2000); (FASB, 2000); (AECA, 2002)).

Na informação contabilístico-financeira divulgada através da Internet, deve haver separação entre a informação que foi objeto de auditoria daquela que ainda não foi? Porquê?

É fundamental que a informação auditada seja separada da não auditada. Quando se está a aceder à informação auditada há a garantia de que esta é credível e que a empresa cumpre com todas as normas e procedimentos do ponto de vista ético, financeiro e até legal para a prossecução dos seus objetivos, ou seja, a auditoria ajuda os utilizadores na redução de equívocos quanto à informação publicada, uma vez que garante a fiabilidade dessa informação. No entanto, segundo a maioria dos entrevistados, ultimamente tem sido prática de algumas empresas de auditoria, com a conivência das empresas auditadas, sonegar informações relevantes da empresa de modo a passar à opinião pública uma imagem mais positiva da empresa, mesmo sabendo da má gestão que nelas se pratica. Esta situação leva os entrevistados a ter algumas reservas quanto às informações que as empresas têm publicado e também quanto à seriedade das auditorias que têm sido feitas, fundamentalmente em instituições bancárias. Também neste tópico se verifica que a opinião dos utilizadores angolanos vai de encontro às diversas recomendações existentes ( (CMVM, 2000); (AECA, 2002); (León, 2003)).

\section{É importante a identificação dos princípios contabilísticos adotados quando se divulga informação contabilístico-financeira através da Internet? Porquê?}

A identificação dos princípios contabilísticos que foram seguidos, segundo os entrevistados, é importante, pois ajudam a perceber os métodos usados para apresentação das contas. É do conhecimento de todos que vários países têm princípios contabilísticos diferentes, mas a opinião dos entrevistados é a de que quando se trate de informação disponibilizada na Internet, por ser informação acessível a partir de qualquer parte do mundo por utilizadores de variados países e realidades diferentes, é importante que se aplique os princípios contabilísticos internacionais, principalmente quando as empresas estão cotadas na bolsa de valores. Esta opinião é, também, coincidente com as orientações dos organismos ( (FASB, 2000); (AECA, 2002)), que recomendam a identificação clara dos Princípios Contabilísticos Geralmente Aceites na preparação da informação contabilístico-financeira apresentada.

Quando há divulgação de informação contabilístico-financeira através da Internet, devem ser indicadas as fontes de informação, quando a mesma não é da responsabilidade da empresa? Porquê? 
A apresentação das fontes, quando se trata de informação contabilístico-financeira divulgada através da Internet e que não é da responsabilidade da empresa, é importante para evitar o risco de se assumir um erro que pode não ter sido cometido pela empresa. Segundo os entrevistados, a apresentação das fontes acrescenta valor relativamente à fiabilidade da informação disponibilizada e, por outro lado, ajuda na busca de mais informações para completar o juízo que se quer fazer desta informação.

As opiniões dos entrevistados coincidem com as recomendações dos organismos ( (CMVM, 2000); (FASB, 2000); (AECA, 2002), que aconselham as empresas a identificar claramente aquela informação que, sendo parte do sítio web, terá sido gerada por terceiros, em cujo caso a fonte deverá ser identificada.

\section{É recomendável a divulgação de informação contabilístico-financeira através da Internet em diferentes idiomas (português e inglês, por exemplo)? Porquê?}

A divulgação da informação contabilístico-financeira em diferentes idiomas é importante, na opinião de todos os entrevistados, na medida em que permite aos diferentes stakeholders efetuar o escrutínio da performance económico-financeira da(s) empresa(s), principalmente quando as empresas estão cotadas na bolsa de valores, porque estão abertas a investidores de qualquer país e a questão do idioma não deve reduzir a potencialidade do mercado.

Também esta opinião dos utilizadores angolanos vai de encontro às recomendações dos organismos ( (CMVM, 2000); (AECA, 2002)) uma vez que, segundo estas entidades, é aconselhável às empresas a difusão noutros idiomas, principalmente em inglês, da sua informação financeira, principalmente para empresas preocupadas em captar investidores no âmbito internacional.

Quando há divulgação de informação contabilístico-financeira através da Internet, devem ser indicadas as datas de publicação/atualização dos documentos? Porquê?

Segundo os entrevistados, é importante a indicação das datas de publicação/atualização dos documentos. O impacto da informação depende do tempo/período em que a mesma é publicada. Quanto mais recente for a informação, maior é o impacto que ela produz nos seus utilizadores. As datas da publicação da informação financeira, ou da sua atualização, permitem aos utilizadores fazer uma análise mais adequada dessa informação. A não atualização da informação leva os utilizadores a efetuar análises desajustadas, uma vez que não sabem qual a data que esta informação relata. Esta necessidade de indicação da data de publicação/atualização da informação financeira na Internet vai de encontro às diversas recomendações ( (CMVM, 2000); (AECA, 2002); (León, 2003)).

Devem ser apresentados contactos específicos (nome, morada, telefone, fax, e-mail) quando há divulgação de informação contabilístico-financeira através da Internet? Porquê?

Todos os entrevistados são de opinião que os contactos específicos são importantes na medida em que ajudam os utilizadores, caso pretendam, a obter mais informações que muitas 
vezes não foram publicadas, o que coincide com as recomendações internacionais ( (CMVM, 2000); (AECA, 2002)).

\section{Quando há divulgação de informação contabilístico-financeira através da Internet, é importante a adoção de medidas de segurança para garantir a autenticidade dos documentos? Porquê?}

A segurança é um fator determinante em todo e qualquer negócio. Quando este é efetuado através da Internet os riscos são maiores. A adoção de medidas de segurança ajuda a proteger a informação contabilístico-financeira divulgada, evitando desta forma que seja adulterada por quem não é o proprietário. Permite, desta forma, proteger a empresa de forma a não correr riscos desnecessários, tanto para a sua imagem e bom-nome, como riscos legais. Por isso, todos os entrevistados são de opinião que devem ser adotadas medidas de segurança para a proteção deste tipo de informação e qualquer outra informação que seja publicada na Internet.

As recomendações que identificámos sobre este tema apontam no sentido da adoção de medidas de segurança razoáveis, conforme defendido por ( (CMVM, 2000); (FASB, 2000); (AECA, 2002)), para evitar a manipulação não autorizada da informação apresentada pelas empresas nos sítios web.

\section{CONCLUSÕES, LIMITAÇÕES E DESENVOLVIMENTOS FUTUROS}

O rápido desenvolvimento das tecnologias de informação e comunicação em geral, e da Internet em particular, tem contribuído para o incremento da entrega e disseminação da informação financeira pelas empresas, sobretudo em países desenvolvidos. Fazem-no, principalmente, porque o uso da Internet na divulgação deste tipo de informação permite captar vários investidores, permite que as informações cheguem a todos os stakeholders no menor tempo possível e com custos muito reduzidos e, não menos importante, contribui para a transmissão de uma imagem de empresa moderna.

Paralelamente, a implementação deste canal de divulgação de informação contabilístico-financeira tem criado novos desafios para gestores e auditores internos, uns responsáveis pela preparação e disseminação da informação, outros responsáveis por estabelecer e rever os controlos necessários para garantir que a informação divulgada cumpre com os requisitos exigidos pela lei.

O desenvolvimento de mercados bolsistas emergentes, como é o caso de Angola, permite que se realize uma análise às necessidades e interesses dos utilizadores deste tipo de informação, de modo a verificar se as atuais recomendações sobre este tipo de divulgação se adequam ou não ao caso em concreto.

Neste trabalho começámos por conhecer o estado da arte para contextualizar o problema em estudo e constatámos que existem diversos organismos e instituições, a nível mundial, preocupadas com a divulgação da informação contabilístico-financeira na Internet. Há estudos que fazem uma análise do relato financeiro eletrónico num determinado país, outros fazem uma comparação entre países e empresas que divulgam a informação contabilístico-financeira na Internet; há ainda estudos que apresentam recomendações quanto à divulgação de informação contabilístico-financeira na Internet e por fim os que analisam e refletem sobre a 
adequabilidade do conteúdo e da forma de apresentação da informação contabilísticofinanceira na Internet.

Destes estudos são poucos os que analisam o conteúdo e a forma de apresentação da informação contabilístico-financeira na perspetiva dos utilizadores. Assim, situámos o nosso estudo neste lado, na procura de informação contabilístico-financeira por parte dos utilizadores, procurando conhecer quais as necessidades, os interesses, a forma e o conteúdo da informação que mais se adequa aos utilizadores num mercado bolsista emergente, como é o caso de Angola.

Os entrevistados manifestaram uma clara preferência pela consulta da informação contabilístico-financeira em formato eletrónico, nomeadamente através dos sítios web, com a possibilidade de aceder à informação através de ficheiros tipo Excel, embora sejam de opinião que o formato PDF é o mais seguro, por não permitir a alteração dos dados. Cerca de metade dos entrevistados é de opinião que deve existir um endereço web/página web específica para este tipo de informação, para facilitar a sua localização. Quanto aos documentos a apresentar pelas empresas, consideram que o Balanço, a Demonstração de Resultados e o Mapa de Fluxos de Caixa são os fundamentais e, preferencialmente, com uma periodicidade semestral, para facilitar o acompanhamento da situação da empresa.

Os entrevistados, unanimemente, entendem que a informação divulgada na Internet deve coincidir com a informação publicada em papel e concordam também na necessidade de separar claramente a informação auditada daquela que não é auditada. São também de opinião que devem ser mencionados os Princípios Contabilísticos Geralmente Aceites que foram seguidos na preparação da informação contabilístico-financeira e que devem ser identificadas as fontes, quando a informação não é da responsabilidade da empresa. Segundo os entrevistados, as fontes acrescentam valor à informação apresentada e ajudam na pesquisa de outras informações.

No que se refere aos idiomas de publicação da informação, os entrevistados também consideram importante o recurso ao inglês, sobretudo para as empresas que pretendem captar investidores de âmbito internacional. Consideram ser importante a indicação das datas de publicação/atualização da informação, pois este dado contribui para uma análise mais correta da informação disponibilizada.

A disponibilização de contactos específicos, como um nome, morada e e-mail, por exemplo, é importante, pois facilita nos casos em que se pretende aceder a mais informações. Por fim, os entrevistados também recomendam a adoção, por parte das empresas, de medidas de segurança que evitem a alteração, não autorizada, dos dados divulgados nos respetivos sítios web.

Em resumo, podemos concluir que os utilizadores da informação contabilísticofinanceira em Angola têm necessidades e interesses, relativamente à informação divulgada através da Internet, coincidentes com as atuais recomendações, identificadas no trabalho de revisão bibliográfica realizado. Esta conclusão é, em nossa opinião, particularmente relevante para as empresas que pretendem integrar o mercado bolsista angolano, pois ao terem em atenção o que os utilizadores querem, estarão a contribuir para um melhor relacionamento entre empresas e investidores, fundamental para captar e manter investidores e para que estes tomem as suas decisões. Paralelamente, esta conclusão também é importante para os organismos 
reguladores angolanos pois constitui um bom ponto de partida para a necessária definição de regras e consequente atividade de controlo.

Este estudo tem como principal limitação o baixo número de entrevistas, o que, simultaneamente, poderá servir de motivação a novos desenvolvimentos, nomeadamente numa fase em que o mercado bolsista angolano esteja mais desenvolvido.

Julgamos ainda que este tipo de análise se poderia fazer noutros países também com mercados bolsistas emergentes. Poderá ainda ser desenvolvido um estudo com países de diferentes regiões do globo de modo a tentarmos perceber se este tipo de questões difere entre regiões ou se as necessidades de informação são comuns e transversais a todos os utilizadores nos mercados financeiros.

\section{REFERÊNCIAS}

AECA (2002). Código de Buenas Prácticas para la Divulgación de Información Financiera en Internet. Madrid: AECA.

Alves, S. (2005). Relato Financeiro na Internet em Portugal. Revista de Gestão da Tecnologia e Sistemas de Informação, 2, 3-20.

Ashbaugh, H., Johnstone, K., \& Warfield, T. (1999). Corporate Reporting on the Internet. Accounting Horizons, 13, 241-257.

Barak, K. (2004). Financial Reporting on the Internet in South Africa. Meditari Accountacy Research, $12,1-20$.

Beattie, V., \& Pratt, K. (2003). Issues concerning web-based Business reporting: an analysis of the views of interested parties. The British Accounting Review, 35, 155-187.

CMVM (2000). Entendimentos e Recomendações da CMVM sobre a utilização da Internet. Obtido de http://www.cmvm.pt/pt/Legislacao/Legislacaonacional/Recomendacoes/Pages/recomendacoes_int ernet.aspx

Craven, B., \& Marston, C. (1999). Financial Reporting on the Internet by Leading UK companies. European Accounting Review, 8, 321-333.

Debreceny, R., Gray, G., \& Mock, T. (2001). Financial Reporting Web Sites: What Users Want in Terms of Form and Content. The International Journal of Digital Accounting Research, 1, 1-23.

Deller, D., Stubenrath, M., \& Goethe, C. (1999). A survey on the Use of the Internet for Investor relations in the USA, the UK and Germany. European Accounting Review, 8, 351-364.

Dominguez, C., \& Gallego, V. (2006). Transparencia de las Páginas Web de las Empresas del IBEX35 - Situación Actual e Implicaciones para el Futuro. Boletín Económico de ICE, 13-25.

FASB (2000). Business Reporting Project - Electronic Distribution of Business Reporting Information. Obtido em 3 de setembro de 2015, de Financial Accounting Standards Board: http://www.fasb.org/cs/ContentServer?c=Document_C\&pagename=FASB\%2FDocument_C\%2FD ocumentPage\&cid $=1175801856611$

Fisher, R., Oyelere, P., \& Laswad, F. (2004). Corporate Reporting on the Internet: Audit Issues and Content Analysis of Practices. Managerial Auditing Journal, 19, 412-439. 
Geerings, J., Bollen, L., \& Hassink, H. (2003). Investor Relations on the Internet: a survey of the Euronext Zone. European Accounting Review, 12, 567-579.

Hedlin, P. (1999). The Internet as a Vehicle for Investor Relations: The Swedish Case. European Accounting Review, 8, 373-381.

IASC (1999). Business Reporting on the Internet. Obtido em 1 de julho de 2001, de http://www.iasc.org.uk

Inchaustin, B., \& Jorge, M. (2002). Qué Información Financiera Ofrecen las Compañias españolas en Internet? Bolsa de Madrid, 38-43.

Larran, M., \& Giner, B. (2002). The Use of the Internet for Corporate Reporting by Spanish Companies. The International Journal of Digital Accounting Research, 2, 53-82.

León, G. (2003). Los riesgos de la información financiera publicada en Internet. Anuario Jurídico y Económico Escurialense, 393-408.

Lymer, A. (1999). Internet and the future of reporting in Europe. European Accounting Review, 8, 289-301.

Lymer, A., Debreceny, R., Gray, G., \& Rahman, A. (1999). Business Reporting on the Internet. London, United Kingdom: International Accounting Standards Committee.

Marston, C. (2003). Financial Reporting on the Internet by Leading Japonese Companies. Corporate Communications: An International Journal, 8, 23-34.

Marston, C., \& Polei, A. (2004). Corporate reporting on the Internet by German companies. International Journal of Accounting Information Systems, 8, 23-34.

O'Kelly, C. (2000). Business reporting on the Internet. Reporting gets personal. Accountacy Ireland, 28-30.

Oyelere, P., Laswad, F., \& Fisher, R. (2003). Determinants of Internet Financial Reporting by New Zealand Companies. Journal of International Financial Management and Accounting, 14, 26-63.

Pérez, C., \& Delgado, C. (2002). Las Empresas Cotizantes en el Mercado de Capitales Mexicano ante los Nuevos Instrumentos de Comunicación de la Información Financiera. Hitos de Ciencias Económico Administrativas, 103-112.

Peréz, M., Martinez, F., \& Martín, J. (2002). Información digital presentada por las entidades financieras españolas: Un estudio empírico. Valladolid.

Pervan, I. (2005). Financial Reporting on the Internet and the Practice of Croatian Joint Stock Companies Quoted on the Stock Exchanges. Financial Theory and Practice, 29, 159-174.

Pirchegger, B., \& Wagenhofer, A. (1999). Financial Information on the Internet: A Survey of the Homepages of Austrian Companies. The European Accounting Review, 8, 383-395.

Quagli, A., \& Riva, P. (November de 2005). Do Financial Websites Meet the Users' Information Needs? A Survey From the Italian Context. Obtido de Social Science Research Network: http://papers.ssrn.com/sol3/papers.cfm?abstract_id=863744

Rodrigues, L., \& Menezes, C. (2001). Relato Financeiro na Internet: Estudo do Caso Português. Jornal do Técnico de Contas e da Empresa, 369-372/402-410.

Salawu, M. (2013). The Extent and Forms of Voluntary Disclosure of Financial Information on Internet in Nigeria: An Exploratory Study. International Journal of Financial Research, 4, 110 119.

Silva, A., \& Quaresma, R. (2001). Análisis de la información presentada en Internet por las empresas: estudio empírico para el caso portugués. Atas del XI Congreso AECA. Madrid: AECA. 
Silva, W., \& Filho, P. (2005). Determinantes da Disseminação Voluntária da Informação Financeira na Internet. RAE-eletrônica, 4.

Smith, B., \& Pierce, A. (2005). An Investigation of the Integrity of Internet Financial Reporting. The International Journal of Digital Accounting Research, 5, 47-78.

Westarp, F., Dieter, O., Stubernat, M., Buxmann, P., \& Konig, W. (1999). Internet-Based Corporate Reporting - Filling the Standardization Gap. Proceedings of the 32nd Annual Hawaii International Conference. Maui, HI, USA: IEEE. doi:10.1109/HICSS.1999.772659

Xiao, J., Yang, H., \& Chow, C. (2004). The determinants and characteristics of voluntary Internetbased disclosures by listed Chinese companies. Journal of Accounting and Public Policy, 2004. 